\title{
WIP: The predictive power of engineering undergraduate students' academic self-efficacy and test anxiety for their academic performance in a dynamics course
}

\section{Daeyeoul Lee, Purdue University}

Daeyeoul Lee is a PhD student in Learning Design and Technology Program at Purdue University. He is a research assistant in the School of Engineering Education at Purdue University. His research focuses on self-regulated learning, motivation, online learning, Massive Open Online Course, and digital technology.

\section{Prof. Jeffrey F Rhoads, Purdue University at West Lafayette}

Jeffrey F. Rhoads is a Professor in the School of Mechanical Engineering at Purdue University and is affiliated with both the Birck Nanotechnology Center and Ray W. Herrick Laboratories at the same institution. He received his B.S., M.S., and Ph.D. degrees, each in mechanical engineering, from Michigan State University in 2002, 2004, and 2007, respectively. Dr. Rhoads' current research interests include the predictive design, analysis, and implementation of resonant micro/nanoelectromechanical systems (MEMS/NEMS) for use in chemical and biological sensing, electromechanical signal processing, and computing; the dynamics of parametrically-excited systems and coupled oscillators; the thermomechanics of energetic materials; additive manufacturing; and mechanics education. Dr. Rhoads is a Member of the American Society for Engineering Education (ASEE) and a Fellow of the American Society of Mechanical Engineers (ASME), where he serves on the Design Engineering Division's Technical Committees on Micro/Nanosystems and Vibration and Sound, as well as the Design, Materials, and Manufacturing (DMM) Segment Leadership Team. Dr. Rhoads is a recipient of numerous research and teaching awards, including the National Science Foundation's Faculty Early Career Development (CAREER) Award; the Purdue University School of Mechanical Engineering's Harry L. Solberg Best Teacher Award (twice), Robert W. Fox Outstanding Instructor Award, and B.F.S. Schaefer Outstanding Young Faculty Scholar Award; the ASEE Mechanics Division's Ferdinand P. Beer and E. Russell Johnston, Jr. Outstanding New Mechanics Educator Award; and the ASME C. D. Mote Jr., Early Career Award. In 2014 Dr. Rhoads was included in ASEE Prism Magazine's 20 Under 40.

\section{Dr. Edward J. Berger, Purdue University at West Lafayette}

Edward Berger is an Associate Professor of Engineering Education and Mechanical Engineering at Purdue University, joining Purdue in August 2014. He has been teaching mechanics for over 20 years, and has worked extensively on the integration and assessment of specific technology interventions in mechanics classes. He was one of the co-leaders in 2013-2014 of the ASEE Virtual Community of Practice (VCP) for mechanics educators across the country. His current research focuses on student problem-solving processes and use of worked examples, change models and evidence-based teaching practices in engineering curricula, and the role of non-cognitive and affective factors in student academic outcomes and overall success.

\section{Prof. Jennifer DeBoer, Purdue University at West Lafayette}

Jennifer DeBoer is currently Assistant Professor of Engineering Education at Purdue University. Her research focuses on international education systems, individual and social development, technology use and STEM learning, and educational environments for diverse learners. 


\section{WIP: The predictive power of engineering undergraduate students' academic self-efficacy and test anxiety for their academic performance in a dynamics course}

\section{Introduction}

Self-regulated learning (SRL) is a vital factor that positively affects students' performance in academic settings, as a wealth of study findings have shown [1], [2]. SRL has received increasing attention from the engineering and technology education research communities as of late [3]. Considering that low academic performance is one of the reasons that a large number of engineering students leave engineering majors and transfer to another major [4], it is important to explore factors that contribute to academic performance in engineering courses. While SRL is broadly understood as an important factor in academic performance, there is a lack of empirical studies on SRL in engineering education settings. As SRL consisting of motivation and learning strategies [5] is dynamic and context-bound [6], students' SRL might be different in engineering courses that mainly focus on disciplinary topics and the acquisition of knowledge [3]. The understanding of engineering students' SRL could provide useful information on how to adjust instructional strategies or how to develop SRL interventions to improve students' academic performance, which ultimately improves the retention rates of engineering students [6].

Engineering education has underestimated the motivational/affective domain of learning and overemphasized the cognitive domain of learning, which has resulted in the non-holistic development of students [7]. In order to help engineering students become self-regulated learners in all three regulation areas that SRL theorists commonly explain, (meta)cognition, motivation, and behavior [8], there is a need to explore and understand how motivational/affective components of SRL work together in engineering education settings. The present study uses Pintrich's SRL model as a theoretical framework and focuses on the self-efficacy and test anxiety constructs, which are included in motivation/affect area for regulation in the model [9]. Self-efficacy is generally described as academic self-efficacy, which refers to students' judgements about their own ability to successfully achieve educational goals [10]. It is task and context-specific [11]. In addition, test anxiety is generally known to be a situation-specific personality trait [12]. Therefore, academic self-efficacy and test anxiety might work differently in different contexts such as difficult engineering courses.

Dynamics is an engineering course with high enrollment that many undergraduate engineering students are required to take [13]. It is widely perceived as one of the most difficult sophomore-level courses by engineering students [13]. Little is known about how academic selfefficacy and test anxiety work together in such a difficult dynamics course. This work-inprogress paper examines the predictive power of engineering undergraduate students' academic self-efficacy and test anxiety with respect to their academic performance in a dynamics course. 


\section{Background Literature}

\section{Theoretical Framework}

The present study used SRL as a theoretical framework. SRL generally refers to "an active, constructive process whereby learners set goals for their learning and then attempt to monitor, regulate and control their cognition, intentions and behavior, guided and constrained by their goals and the contextual features of the environment" [14, p. 453]. Self-regulated learners incorporate diverse self-regulation processes such as goal settings with learning strategies such as time management and self-motivational beliefs such as self-efficacy [15]. Pintrich and his colleagues developed the Motivated Strategies for Learning Questionnaire (MSLQ) to measure college students' SRL skills [5], and he proposed a conceptual framework for SRL in the college classroom [9]. The framework consists of four phases that are explained in four areas for regulation; the four phases are 'forethought, planning, and activation,' 'monitoring,' 'control,' and 'reaction and reflection'; the four areas for regulation are 'cognition,' 'motivation/affect,' 'behavior,' and 'context.' Table I shows Pintrich's SRL model [9].

TABLE I

PHASES AND AREAS FOR SELF-REGULATED LEARNING

\begin{tabular}{|c|c|c|c|c|}
\hline & \multicolumn{4}{|c|}{ Areas for regulation } \\
\hline $\begin{array}{c}\text { Phases and } \\
\text { relevant } \\
\text { scales }\end{array}$ & Cognition & $\begin{array}{c}\text { Motivation/ } \\
\text { Affect }\end{array}$ & Behavior & Context \\
\hline $\begin{array}{l}\text { Phase } 1 \\
\text { Forethought, } \\
\text { planning, and } \\
\text { activation }\end{array}$ & $\begin{array}{l}\text { Target goal } \\
\text { setting } \\
\text { Prior content } \\
\text { knowledge } \\
\text { activation } \\
\text { Metacognitive } \\
\text { knowledge } \\
\text { activation }\end{array}$ & $\begin{array}{l}\begin{array}{l}\text { Goal orientation } \\
\text { adoption }\end{array} \\
\text { Efficacy } \\
\text { judgements } \\
\text { Perceptions of } \\
\text { task difficulty } \\
\text { Task value } \\
\text { activation } \\
\text { Interest } \\
\text { activation }\end{array}$ & $\begin{array}{l}\text { Time and effort } \\
\text { planning } \\
\text { Planning for self- } \\
\text { observations of } \\
\text { behavior }\end{array}$ & $\begin{array}{l}\text { Perceptions of } \\
\text { task } \\
\text { Perceptions of } \\
\text { context }\end{array}$ \\
\hline $\begin{array}{l}\text { Phase } 2 \\
\text { Monitoring }\end{array}$ & $\begin{array}{l}\text { Metacognitive } \\
\text { awareness and } \\
\text { monitoring of } \\
\text { cognition }\end{array}$ & $\begin{array}{l}\text { Awareness and } \\
\text { monitoring of } \\
\text { motivation and } \\
\text { affect }\end{array}$ & $\begin{array}{l}\text { Awareness and } \\
\text { monitoring of } \\
\text { effort, time use, } \\
\text { need for help } \\
\text { Self-observation of } \\
\text { behavior }\end{array}$ & $\begin{array}{l}\text { Monitoring } \\
\text { changing task and } \\
\text { context } \\
\text { conditions }\end{array}$ \\
\hline
\end{tabular}




\begin{tabular}{|c|c|c|c|c|}
\hline $\begin{array}{l}\text { Phase } 3 \\
\text { Control }\end{array}$ & $\begin{array}{l}\text { Selection and } \\
\text { adaptation of } \\
\text { cognitive } \\
\text { strategies for } \\
\text { learning, } \\
\text { thinking }\end{array}$ & $\begin{array}{l}\text { Selection and } \\
\text { adaptation of } \\
\text { strategies for } \\
\text { managing, } \\
\text { motivation and } \\
\text { affect }\end{array}$ & $\begin{array}{l}\text { Increase/ decrease } \\
\text { effort } \\
\text { Persist, give up } \\
\text { Help-seeking } \\
\text { behavior }\end{array}$ & $\begin{array}{l}\text { Change of } \\
\text { renegotiate task } \\
\text { Change of leave } \\
\text { context }\end{array}$ \\
\hline $\begin{array}{l}\text { Phase } 4 \\
\text { Reaction and } \\
\text { reflection }\end{array}$ & $\begin{array}{l}\text { Cognitive } \\
\text { judgements } \\
\text { Attributions }\end{array}$ & $\begin{array}{l}\text { Affective } \\
\text { reactions } \\
\text { Attributions }\end{array}$ & Choice behavior & $\begin{array}{l}\text { Evaluation of task } \\
\text { Evaluation of } \\
\text { context }\end{array}$ \\
\hline $\begin{array}{l}\text { Relevant } \\
\text { MSLQ } \\
\text { Scales }\end{array}$ & $\begin{array}{l}\text { Rehearsal } \\
\text { Elaboration } \\
\text { Critical thinking } \\
\text { Metacognition }\end{array}$ & $\begin{array}{l}\text { Intrinsic goals } \\
\text { Extrinsic goals } \\
\text { Task value } \\
\text { Control beliefs } \\
\text { Self-efficacy } \\
\text { Test anxiety }\end{array}$ & $\begin{array}{l}\text { Effort regulation } \\
\text { Help-seeking } \\
\text { Time/study } \\
\text { environment }\end{array}$ & $\begin{array}{l}\text { Peer learning } \\
\text { Time/study } \\
\text { environment }\end{array}$ \\
\hline
\end{tabular}

The present study focuses on motivation/affect area for regulation, in particular, selfefficacy and test anxiety in the Pintrich's model [9]. They are bolded in Table I. The following section addresses literature on these two components in relation to academic performance.

\section{Factors Contributing to Students' Academic Performance in Engineering Education Settings}

Academic self-efficacy

Self-efficacy is defined as "people's beliefs about their capabilities to produce designated levels of performance that exercise influence over events that affect their lives" [16, p. 71]. Selfefficacy is generally described as academic self-efficacy, which refers to students' judgements about their own ability to successfully achieve educational goals [10]. Academic self-efficacy significantly predicts academic performance in general academic settings, as shown in systematic reviews on academic self-efficacy [17]. With the importance of self-efficacy, it has received much attention from researchers and educators in engineering education settings. However, different self-efficacy constructs such as mathematic self-efficacy [18] and engineering selfefficacy [19] have been interchangeably used and examined without a clear distinction. This has led to the limited understanding of academic self-efficacy in engineering education settings. As self-efficacy is task and context-specific [11], [20], engineering students might have different self-efficacy beliefs in each course that they take.

Some researchers have recently emphasized the role of students' academic self-efficacy in engineering education [21]. However, it has been mainly explained based on theories such as 
goal theory. A few studies have examined the effects of engineering undergraduate students' academic self-efficacy on their academic performance. However, findings of the studies were not consistent. For example, the findings of Haron and Shaharoun's study [22] indicated that Malaysian engineering undergraduate students' academic self-efficacy significantly predicted their academic performance. On the other hand, in Alias, Akasah, and Kesot's study [23], there was no significantly positive correlation between academic self-efficacy and academic performance of engineering students from two public technical universities in Malaysia. Therefore, there is a need to further examine the relationship between academic self-efficacy and academic performances in engineering education settings.

\section{Test anxiety}

Test anxiety is generally defined as "the set of phenomenological, physiological, and behavioral responses that accompany concern about possible negative consequences or failure on an exam or similar evaluative situation" [24, p. 17]. It is a multidimensional construct and one of the motivational/affective components of SRL [1]. In the MSLQ, text anxiety scale consists of two components: worry and emotionality; The worry component is defined as negative ideas and thoughts that disrupt students' performance while the emotionality component refers to physiological responses to anxiety [5].

Several empirical study findings showed the negative effects of test anxiety on academic performance in general academic settings [25] - [27]. In engineering education settings, a few studies have examined the effects of test anxiety on academic performance. However, because some previous studies have used an unreliable test anxiety survey [21], [28], there is a need to further explore them by using a survey with reliability. Hsieh, Sullivan, Sass and Guerra established the reliability of test anxiety survey items in their study [29]. They found that engineering undergraduate students' test anxiety did not significantly predict academic performance. In their study, it was a significantly negative predictor of academic self-efficacy. This result is not consistent with study findings in general academic settings, which raises a question of whether it is generalizable to other engineering courses. More empirical studies are needed to answer to the question.

Based on the literature reviewed above, the present study has the following research question:

RQ. Do engineering undergraduate students' academic self-efficacy and test anxiety predict their academic performance in a dynamics course?

\section{Methods}

\section{Study Setting}

This study was conducted in the dynamics course in the mechanical engineering department at a large public Midwestern university. The dynamics course is a pre-requisite course for all students who major in mechanical engineering at the university. In 2008, an active, 
blended, and collaborative (ABC) learning environment called Freeform developed by three professors was implemented in the dynamics course [30]. Since the implementation of Freeform, the rate of students who earned a D, F, or withdrew from the dynamic course decreased by half [31]. Freeform has five fundamental elements: student-centered in-class instruction, a course "lecture book" that is a combination of a workbook and a textbook, a course blog, lecture examples and homework solution videos, and student assessment tools such as an abbreviated Dynamics Concept Inventory [30], [32]. In the 2019 spring semester, the dynamics course had four sections. All of the sections were taught by different instructors. However, they used same homework, exams, and resources to ensure consistency across instructors.

\section{Instruments}

Eight academic self-efficacy items and five test anxiety items from the MSLQ [5] were used. They have been widely used to measure self-efficacy and test anxiety in college settings [26], [33]. They used a 7-point Likert scale ranging from "not at all true of me" to "very true of me." The academic self-efficacy items were slightly modified to better fit the dynamics course. Specifically, the phrase of 'the course' in the self-efficacy items was changed to 'ME 274' to reflect the specific dynamic course number. For example, 'I am certain I can understand the most difficult material presented in this course' was changed to 'I am certain I can understand the most difficult material presented in ME 274.' The reliability of the self-efficacy and test anxiety items were checked by Cronbach's $\alpha$ values, which were .91 and .78 respectively.

\section{Recruitment and Participants}

Once Institutional Review Board approval was granted, a survey was administered in the classrooms at the end of the dynamics course. Students who were interested in participating in this study completed a consent form and took the survey. The survey was voluntary, and if students completed it, they received a small amount of extra credit. At the end of semester, the students' final grades were collected from the instructors. The participants in this study were 385 engineering undergraduate students who enrolled in a dynamics course. Of the 385 students, 299 students responded to the survey.

\section{Data Analysis}

Data were analyzed by using inferential statistics in SPSS. Because 10 students did not complete the full survey, their responses were removed from data analysis. In addition, as 12 outliers were detected for multiple linear regression, they were also removed. Finally, 277 student responses were analyzed.

In order to address the research question, multiple linear regression analysis and simple linear regression analysis were conducted. Prior to conducting each analysis, all assumptions were checked: a linear relationship, homoscedasticity, multicollinearity, and independent errors by the residuals. They are represented in the following section.

\section{Results}

The Result of Multiple Linear Regression Analysis 
Prior to conducting stepwise multiple regression analysis, all assumptions for multiple linear regression were checked. First, a linear relationship between academic self-efficacy and test anxiety was identified by a scatterplot. Second, the results of The Breusch-Pagan test [34] indicated that there was no homoscedasticity $(p>.05)$. Third, variance inflation factor values, which were lower than 10, indicate that there was no multicollinearity between self-efficacy and test anxiety. Finally, the result of the Durbin-Watson test was 2.30, showing that there were no independent errors by the residuals.

In terms of stepwise multiple regression analysis, academic self-efficacy was entered into the regression model. The model 1 was statistically significant with $F(1,281)=44.33, p<.01$. It accounted for approximately $13 \%$ of the variance of academic performance (adjusted $R^{2}=.13$ ). On the next step, test anxiety was excluded to the regression model because it did not make a statistically significant addition to the current regression equation. While academic self-efficacy was a significant predictor of academic performance $(\beta=.37, p<.05)$, test anxiety did not significantly predict academic performance.

\section{The Result of Simple Linear Regression Analysis}

In order to further examine whether test anxiety predicts academic self-efficacy, simple linear regression analysis was additionally conducted. The simple linear regression model was statistically significant $(\mathrm{F}(1,275)=36.39, \mathrm{p}<.01)$ and showed that academic self-efficacy accounted for approximately $11 \%$ of the variation of test anxiety (adjusted $\mathrm{R}^{2}=.11$ ). The result of simple linear regression analysis showed that test anxiety negatively predicted academic selfefficacy $(\beta=-.34, p<.05)$.

\section{Discussion and Conclusion}

The present study examines the predictive power of engineering undergraduate students' academic self-efficacy and test anxiety for their academic performance in a dynamics course.

\section{RQ. Do Engineering Undergraduate Students' Academic Self-Efficacy and Test Anxiety Predict Their Academic Performance in a Dynamics Course?}

The results of the stepwise multiple regression analysis showed that engineering undergraduate students' academic self-efficacy significantly predicted their academic performance in a dynamics course, which is congruent with Haron and Shaharoun's study findings [22]. While previous study findings showed academic self-efficacy both as a significant predictor of academic performance and not a significant predictor, which were inconsistent [22], [23], this study finding provides empirical evidence of the positive effect of academic selfefficacy on academic performance in a dynamics (core engineering science) class. This study finding supports the vital role of academic self-efficacy, which has been increasingly emphasized in engineering education [21]. Given the importance of academic self-efficacy, instructors should help engineering undergraduate students develop their academic self-efficacy. Although little is known about best practice of improving students' self-efficacy in engineering classes, literature on self-efficacy could provide suggestive insights on instructional strategies or interventions to 
enhance engineering students' self-efficacy. For instance, four sources of self-efficacy proposed by Bandura [11] should be considered in developing and implementing instructional strategies to improve students' academic self-efficacy in engineering education settings: enactive mastery experiences, vicarious experiences, verbal persuasion, and physiological and affective factors. As a practical example, as Getachew and Birhane [35] suggested, engineering instructors could start the lesson with a review and ask students to record each day on a calendar something new they learned at the end of the lesson for promoting enactive mastery experiences. In addition, instructors could help students set clear and specific goals at the beginning of semester, because goal setting affects students' initial self-efficacy beliefs for achieving the goal [11].

On the other hand, engineering undergraduate students' test anxiety was not a significantly negative predictor of their academic performance in a dynamics course, which is consistent with Hsieh, et al.'s study finding [29]. The findings of the present study show that the predictive power of test anxiety for academic performance in engineering education settings is different from that in general academic settings. Although this difference has not been fully explained in literature, test anxiety might have more significant effects on other motivational/affective variables than directly on academic performance in engineering education settings. When academic self-efficacy and test anxiety worked together in a dynamics course, test anxiety significantly predicted academic self-efficacy rather than academic performance, which is congruent with Hsieh, et al.'s study findings [29]. As shown in Table I, within Pintrich's SRL framework [9], engineering undergraduate students regulated their motivation and affect in a dynamics course. When they had test anxiety as affective reaction, it affected judgements of their own self-efficacy beliefs. This is supported by the fact that the four phases of SRL model are not always linear or hierarchical [9] and test anxiety is a negative predictor of academic self-efficacy in general academic settings [31].

In conclusion, the findings of this study direct engineering educators to emphasize the key role of academic self-efficacy. They provide new insights on how motivational/affective constructs of SRL are related to each other and predict academic performance in a dynamics course. The present study contributes to the study body of SRL, especially, academic selfefficacy and test anxiety, in engineering education settings.

\section{Limitations and Future Research}

There are limitations to this study. First, this study was conducted in an $\mathrm{ABC}$ learning environment, which was different from a traditional dynamics course. In order to identify the generalizability of findings of this study, future research should examine other dynamics courses. Second, the study findings were drawn from self-reported questionnaires. Future research should employ qualitative research methods or mixed methods to deeply explore how individual engineering student's self-efficacy and test anxiety affect their academic performance. Third, the scope of this study is limited to examine academic self-efficacy and test anxiety in motivation/affect area for regulation in Pintrich's model [9]. Researchers should further explore how other cognitive constructs such as metacognition, behavior constructs such as help-seeking, or motivational constructs predict academic performance in dynamics courses. Fourth, this study used test anxiety items from the MSLQ within a theoretical framework of Pintrich's [9] SRL 
model. In order to examine other dimensions of test anxiety, such as test preparation, which were not measured in this study, other survey items could be used in the future research. Lastly, future research should investigate the effects of instructional strategies to improve students' academic self-efficacy in a dynamics course.

\section{Acknowledgements}

This material is based on work supported by the National Science Foundation, Division of Undergraduate Education under Grant Number 1525671. Any opinions, findings, and conclusions or recommendations expressed in this material are those of the authors and do not necessarily reflect the views of the National Science Foundation.

\section{References}

[1] P. R. Pintrich and E. V. De Groot, "Motivational and self-regulated learning components of classroom academic performance," J. Educ. Psychol, vol. 82, no. 1, pp. 33-40, 1999.

[2] B. J. Zimmerman, "Investigating self-regulation and motivation: Historical background, methodological developments, and future prospects," Amer. Educ. Res. J, vol. 45, no. 1, pp. 166-183, 2008.

[3] H. R. Shih, W. Zheng, E. J. Leggette, and G. Skelton, "Enhancing student performance by promoting Self-regulated learning." in ASME 2011 International Mechanical Engineering Congress and Exposition, Denver, CO, USA, November 11-17, 2011, pp. 469-477.

[4] B. N. Geisinger and D. R. Raman, "Why they leave: Understanding student attrition from engineering majors," Int. J. Eng. Edu, vol. 29, no. 4, pp. 914-925, 2013.

[5] P. R. Pintrich, D. A. F. Smith, T. Garcia and W. J. McKeachie, A manual for the use of the Motivated Strategies for Learning Questionnaire (MSLQ). Ann Arbor, Michigan: The University of Michigan, 1991.

[6] S. Y. Chyung, A. J. Moll and S. A. Berg, "The role of intrinsic goal orientation, selfefficacy, and e-learning practice in engineering education," J. Effect. Teach, vol. 10, no. 1, pp. 22-37, 2010.

[7] M. Alias, Z. A. Akasah, and M. J. Kesot, "Self-efficacy, locus of control and attitude among engineering students: Appreciating the role of affects in learning efforts," in International Conference on Teaching and Learning in Higher Education (ICTLHE 2012), Malaysia, pp. 183-190.

[8] B. J. Zimmerman, "Becoming a self-regulated learner: Which are the key subprocesses?" Contemp. Edu. Psychol. vol. 11. no. 4, pp. 307-313, 1986. 
[9] P. R. Pintrich, "A conceptual framework for assessing motivation and self-regulated learning in college students," Educ. Psychol. Rev, vol. 16, no. 4, pp. 385-407, 2004.

[10] S. M. Elias and S. MacDonald, "Using past performance, proxy efficacy, and academic self-efficacy to predict college performance," J. Appl. Soc. Psychol, vol. 37, no. 11, pp. 2518-2531, 2007.

[11] A. Bandura, Self-Efficacy: The Exercise of Control, NY: W. H. Freeman and Company, 1997.

[12] C. D. Spielberger, Test Anxiety Inventory: Preliminary Professional Manual, Palo Alto, CA: Consulting Psychologists Press, 1980.

[13] S. Huang and N. Fang, "Predicting student academic performance in an engineering dynamics course: A comparison of four types of predictive mathematical models," Computer. Edu, vol. 61, pp. 133-145, 2013.

[14] P. R. Pintrich, "The role of goal orientation in self-regulated learning," in Handbook of self-regulation, M. Boekaerts, P. R. Pintrich, and M. Zeidner, Eds. San Diego: Academic Press, 2000, pp. 451-502.

[15] T. J. Cleary and B. J. Zimmerman, "Self-regulation empowerment program: A schoolbased program to enhance self-regulated and self-motivated cycles of student learning," Psychol. School, vol. 41, no. 5, pp. 537-550, 2004.

[16] A. Bandura, "Self-efficacy," in Encyclopedia of Human Behavior, V. S. Ramachaudran, Ed. New York: Academic Press, pp. 71-81, 1994.

[17] T. Honicke and J. Broadbent, "The influence of academic self-efficacy on academic performance: A systematic review," Edu. Res. Rev, vol. 17, pp. 63-84, 2016.

[18] C. W. Loo, and J. L. F. Choy, "Sources of self-efficacy influencing academic performance of engineering students," Amer. J. Educ. Res, vol. 1, no. 3, pp. 86-92, 2013.

[19] J. P. Concannon and L. H. Barrow, "A cross-sectional study of engineering students' selfefficacy by gender, ethnicity, year, and transfer status," J. Sci. Edu. Technol, vol. 18, no. 2, pp. 163-172, 2009.

[20] B. J. Zimmerman, "Self-efficacy: An essential motive to learn," Contemp. Edu. Psychol, vol. 25 , no. 1, pp. 82-91, 2000.

[21] M. K. Ponton, J. H. Edmister, L. S. Ukeiley, and J. M. Seiner, "Understanding the role of self-efficacy in engineering education,” J. Eng. Edu, vol. 90, no. 2, pp. 247-251, 2001.

[22] H. N. Haron and A. M. Shaharoun, "Self-regulated learning, students' understanding and performance in engineering statics," in 2011 IEEE Global Engineering Education Conference, Jordan, April 4-6, 2011. 
[23] M. Alias, Z. A. Akasah and M. J. Kesot, "Relationships between locus of control, selfefficacy, efforts and academic achievement among engineering students." in the $3^{\text {rd }}$ International Conference on Industrial Engineering and Applications, Hong Kong, April 28-30, 2016.

[24] M. Zeidner, Test Anxiety: The State of the Art. New York: Plenum Press, 1998.

[25] A. Kitsantas, A. Winsler, and F. Huie, "Self-regulation and ability predictors of academic success during college: A predictive validity study," J. Adv. Acad, vol. 20, no. 1, pp. 4268, 2008.

[26] M. S. Chapell et al., "Test anxiety and academic performance in undergraduate and graduate students,” J. Edu. Psychol, vol. 97, no. 2, pp. 268-274, 2005.

[27] E. Hong, and L. Karstensson, “Antecedents of state test anxiety," J. Contemp. Edu. Psychol, vol. 27, no. 2, pp. 348-367, 2002.

[28] H. N. Haron, H. Harun, R. Ali, K. R. Salim, and N. H. Hussain, "Self-regulated learning strategies between the performing and non-performing students in statics," in 2014 International Conference on Interactive Collaborative Learning (ICL), Dubai, United Arab Emirates, pp. 802-805, 2014.

[29] P. H. Hsieh, J. R. Sullivan, D. A. Sass, and N. S. Guerra, "Undergraduate engineering students' beliefs, coping strategies, and academic performance: An evaluation of theoretical models," J. Exp. Edu, vol. 80, no. 2, pp. 196-218, 2012.

[30] J. Rhoads, E. Nauman, B. Holloway, and C. Krousgrill, "The Purdue mechanics Freeform classroom: A new approach to engineering mechanics education," in 121st ASEE Annual Conference and Exposition. Indianapolis, IN, USA, June 15-18, 2014.

[31] J. DeBoer et al., "Work in Progress: rigorously assessing the anecdotal evidence of increased student persistence in an Active, Blended, and Collaborative Mechanical Engineering environment," in 2016 ASEE Annual Conference and Exposition, New Orleans, LA, USA, June 26-29, 2016.

[32] N. Stites et al. "Analyzing an abbreviated dynamics concept inventory and its role as an instrument for assessing emergent learning pedagogies," in 2016 ASEE Annual Conference and Exposition, New Orleans, LA, USA, June 26-29, 2016.

[33] M. Birenbaum, "Assessment and instruction preferences and their relationship with test anxiety and learning strategies," High. Edu, vol. 53, no. 6, pp. 749-768, 2007.

[34] T. S. Breusch and A. R. Pagan, "A simple test for heteroscedasticity and random coefficient variation,” Econometrica, vol. 47, no. 5, pp. 1287-1294, 1979. 
[35] K. Getachew and A. Birhane, "Improving students' self-efficacy and academic performance in Applied Mathematics through innovative classroom-based strategy at Jimma University, Ethiopia,” Tun. J. High. Edu, vol. 4, no. 1, pp. 119-143, 2016. 